\title{
Influência do Tipo E da Guantidade de Resíduos Vegetais NA Emergência de Plantas Daninhas ${ }^{1}$
}

\author{
Influence of Type and Amount of Crop Residues on Weed Emergence
}

CORREIA, N.M. ${ }^{2}$, DURIGAN, J.C. ${ }^{2}$ e KLINK, U.P. ${ }^{3}$

\begin{abstract}
RESUMO - Com o objetivo de avaliar os efeitos da semeadura no outono/inverno de diferentes espécies: sorgo de cobertura (Sorghum bicolor x Sorghum sudanense 'híbrido Cober Exp'), milheto forrageiro (Pennisetum americanum 'var. BN2'), capim-pé-de-galinha (Eleusine coracana) e braquiária (Brachiaria brizantha) para formação de palha (nas quantidades de 3,0 e 5,5 t ha-1), na emergência de plantas daninhas, foi conduzido experimento no ano agrícola 2003/04, na fazenda Três Marcos, em Uberlândia, MG. Foi mantida uma testemunha como tratamento adicional, sem cobertura com restos vegetais. A composição específica e as densidades populacionais das comunidades infestantes foram influenciadas pelos sistemas de produção de cobertura morta. A emergência das plantas daninhas foi menor nas coberturas de sorgo e braquiária e nos maiores níveis de palha. O número de plântulas emergidas de Bidens pilosa, Amaranthus spp., Commelina benghalensis, Leucas martinicensis e gramíneas foi inibido pelas coberturas, enquanto para Chamaesyce spp. os resíduos contribuíram para incremento na sua emergência.
\end{abstract}

Palavras-chave: Brachiaria brizantha, cobertura do solo, Eleusine coracana, Pennisetum americanum, Sorghum bicolor, Sorghum sudanense.

ABSTRACT - To evaluate the effects on weed emergence of autumn/winter sowing of different species [sorghum (Sorghum bicolor $\boldsymbol{x}$ Sorghum sudanense 'Cober Exp hybrid'), forage millet (Pennisetum americanum 'var. BN2'), finger millet (Eleusine coracana) and St Lucia grass (Brachiaria brizantha), for mulch formation (at rates of 3.0 and $5.5 t^{2} \mathrm{~h}^{-1}$ ), an experiment was carried out in the agricultural year 2003/2004, in Uberlândia, Minas Gerais, Brazil. The specific composition and population densities of the infesting community were influenced by the mulch production systems. Weed emergence was minor under sorghum and Sta Lucia grass cover and in greater amounts of straw. Straw cover inhibited the emergence of seedlings of Bidens pilosa, Amaranthus spp., Commelina benghalensis, Leucas martinicensis and grasses and stimulated the emergence of Chamaesyce spp.

Keywords: Brachiaria brizantha, Eleusine coracana, Pennisetum americanum, soil cover, Sorghum bicolor, Sorghum sudanense.

\section{INTRODUÇÃO}

A palha mantida sobre o solo no sistema de semeadura direta de culturas agrícolas pode afetar a emergência das plantas daninhas por três processos distintos: o físico, o biológico e o químico, com possiveis interações entre eles
(Pitelli \& Durigan, 2001). O efeito físico é importante para sementes fotoblásticas positivas e para aquelas que necessitem de grande amplitude de variação térmica diária para iniciar o processo germinativo (Buzatti, 1999; Theisen \& Vidal, 1999; Pitelli \& Durigan, 2001). Além disso, o efeito físico da palha reduz

Recebido para publicação em 18.7.2005 e na forma revisada em 5.5.2006.

2 Eng.-Agro. Dr., Professor do Departamento de Fitossanidade da UNESP, Campus de Jaboticabal, Via de Acesso Prof. Paulo Donato Castellane, s/n, 14884-900 Jaboticabal-SP, <correianm@ @cav.unesp.br>, <jcdurigan@ fcav.unesp.br>. ${ }^{3}$ Eng.-Agr ${ }^{\circ}$. M.S., Gerente de Pesquisa da Monsanto do Brasil Ltda., <urubatan.p.klink@monsanto.com>. 
as chances de sobrevivência das plântulas com pequena quantidade de reservas nas sementes. Algumas ações biológicas podem ser beneficiadas pela presença da palha, pois esta cria condições para instalação de uma densa e diversificada microbiocenose na camada superficial do solo. De maneira geral, os microrganismos exercem importantes funções na deterioração e perda de viabilidade dos diversos tipos de diásporos e plântulas no solo (Pitelli \& Durigan, 2001). Além disso, deve-se considerar que a palha cria abrigo seguro para alguns insetos, roedores e outros pequenos animais, que se alimentam de sementes e partes aéreas das plantas daninhas (Theisen \& Vidal, 1999; Pitelli \& Durigan, 2001). Os efeitos químicos estão relacionados com fenômenos alelopáticos, alterações na relação carbono/nitrogênio $(\mathrm{C} / \mathrm{N})$, imobilização e reciclagem de nutrientes.

Várias pesquisas têm sido realizadas visando a avaliação do manejo dos resíduos vegetais no controle de plantas daninhas. No Brasil, foi demonstrada a eficácia de controle da palha de diversas culturas, detectando-se até uma relação de seletividade na interação palha-planta daninha (Durigan \& Almeida, 1993).

A esse respeito, constatou-se que a emergência da comunidade infestante foi afetada pelas quantidades de palha de milho mantidas sobre o solo. Para cada tonelada de palha adicionada, houve controle de aproximadamente $4,0 \%$ no total das plantas daninhas (Oliveira et al., 2001).

A manutenção da palha de centeio na superfície do solo reduziu em 75 a $80 \%$ a emergência das plântulas de Amaranthus retroflexus, Chenopodium album, Ambrosia artemisifolia, Ipomoea spp., Sida spinosa e Senna obtusifolia, nas culturas em sucessão (soja, fumo, milho e sorgo). Com a remoção da palha e o preparo do solo, observou-se pequena ou nenhuma redução destas espécies (Nagabhushana et al., 2001).

A cobertura do solo com 5, 10 e $15 \mathrm{t} \mathrm{ha}^{-1}$ de palha de cana-de-açúcar inibiu a emergência das plântulas de Brachiaria decumbens e Sida spinosa. O mesmo foi observado para Digitaria horizontalis submetida a 10 e 15 t ha $^{-1}$ de palha. No entanto, para Ipomoea grandifolia e Ipomoea hederifolia o número de plântulas emergidas não diferiu entre as quantidades estudadas. Contudo, a presença da cobertura morta com palha de cana incrementou a emergência de plântulas de Ipomoea quamoclit (Correia \& Durigan, 2004).

Aos 22 dias após a deposição da palha de sorgo sobre o solo, as densidades populacionais de Brachiaria plantaginea e Sida rhombifolia foram reduzidas em 31 e 44\%, respectivamente. Aos 50 dias, as reduções foram de 36 e $43 \%$, respectivamente (Trezzi \& Vidal, 2004).

Com palha de sorgo-de-guiné-gigante (Sorghum bicolor subsp. bicolor raça guinea), o aporte de $5 \mathrm{t} \mathrm{ha}^{-1}$ proporcionou redução de 66 e 54\% das espécies de gramíneas e de latifoliadas, respectivamente. A adição de $15 \mathrm{t} \mathrm{ha}^{-1}$ reduziu 95\% das gramíneas e 90\% das latifoliadas, quando comparada à ausência de palha (Mateus et al., 2004).

O objetivo do presente trabalho foi avaliar, em condições de campo e na região originalmente sob cerrado, os efeitos dos tipos e das quantidades de resíduos vegetais, produzidos in locu, na emergência de plantas daninhas.

\section{MATERIAL E MÉTODOS}

O experimento foi conduzido durante o período de fevereiro de 2003 a janeiro de 2004, em condições de campo, na Fazenda Três Marcos, localizada em Uberlândia, MG. A altitude do local é de, aproximadamente, 872 metros, com latitude de $18^{\circ} 55^{\prime} \mathrm{S}$ e longitude de $48^{\circ} 17^{\prime} \mathrm{W}$. Segundo a classificação de Köeppen, o clima da região é do tipo Aw. O solo da área experimental é representativo da região, classificado como Latossolo VermelhoAmarelo distroférrico, textura argilosa, originalmente sob vegetação de cerrado, submetido ao sistema de semeadura direta há quatro anos, com as culturas milho/sorgo no inverno e soja/crotalária no verão.

O delineamento experimental utilizado foi o de blocos ao acaso, num esquema de parcelas subdivididas, com quatro repetições. Foram mantidos quatro tipos de cobertura nas parcelas: sorgo de cobertura (Sorghum bicolor $x$ S. sudanensis 'Cober Exp'), milheto forrageiro (Pennisetum americanum 'BN2'), 
capim-pé-de-galinha (Eleusine coracana) e braquiária (Brachiaria brizantha). Nas subparcelas, foram formadas duas quantidades (3,0 e 5,5 $\mathrm{t} \mathrm{ha}^{-1}$ ) de palha. Além disso, mantevese uma testemunha como tratamento adicional, sem cobertura com restos vegetais.

As culturas de cobertura foram instaladas na última semana de fevereiro de 2003 e, para obtenção das duas quantidades de palha, variaram-se as densidades de semeadura de milheto forrageiro (10 e $15 \mathrm{~kg} \mathrm{ha}^{-1}$ ), capim-péde-galinha (5 e $10 \mathrm{~kg} \mathrm{ha}^{-1}$ ) e braquiária $(4,5 \mathrm{e}$ $18 \mathrm{~kg} \mathrm{ha}^{-1}$ ), todas semeadas a lanço. O sorgo de cobertura foi semeado na quantidade de $15 \mathrm{~kg} \mathrm{ha}^{-1}$, a lanço e em linha.

As culturas foram conduzidas até o fim do ciclo das plantas, ocorrendo a produção de sementes, que foram, juntamente com os outros resíduos vegetais, depositadas no solo, com auxílio de uma roçadora, no mês de julho.

Na segunda quinzena do mês de outubro, fez-se a dessecação da área experimental, utilizando-se o herbicida glyphosate na dosagem de 1,44 $\mathrm{kg} \mathrm{ha}^{-1}$ de equivalente ácido. Após sete dias, as parcelas com braquiária foram novamente tratadas com glyphosate na mesma dosagem.

Após a formação da cobertura morta, foi realizada uma amostragem em cada subparcela, para quantificação do equivalente em palha por hectare. Dentro da área útil de cada subparcela foram coletados os resíduos vegetais, numa área de $0,25 \mathrm{~m}^{2}$, em quatro pontos escolhidos aleatoriamente. A palha coletada foi cuidadosamente peneirada e limpa com o auxílio de um pincel, para retirar as partículas de solo a ela aderidas. As amostras foram acondicionadas em sacos de papel e encaminhadas ao laboratório para pesagem. Através de análise estatística, pelo teste de Tukey a 5\% de probabilidade, constatou-se que dentro de cada nivel de palha não havia diferença entre os tipos de cobertura, com os valores de 3,0 e $5,5 \mathrm{t} \mathrm{ha}^{-1}$.

Cada subparcela foi constituída de área com $12 \mathrm{~m}^{2}$ (3x4 m), delimitando-se uma área útil de $6 \mathrm{~m}^{2}(2 \times 3 \mathrm{~m})$, onde foram executadas as avaliações.

O número de plântulas emergidas foi obtido aos 14 dias após a quantificação (DAQ) da palha e aos 75 DAQ, quando a emergência já havia estabilizado. As plântulas emergidas foram contabilizadas numa área de $1 \mathrm{~m}^{2}$, demarcada aleatoriamente dentro da área útil de cada unidade experimental. Aos 75 DAQ, foi realizada a coleta da parte aérea das plantas daninhas, com o intuito de se determinar a matéria seca delas. O material foi acondicionado em sacos de papel e levado à estufa com circulação forçada de ar, mantido a $65{ }^{\circ} \mathrm{C}$, até atingir massa constante.

A comunidade infestante da área experimental foi composta principalmente por espécies dicotiledôneas: Bidens pilosa, Chamaesyce spp., Amaranthus spp. e Leucas martinicensis, com 38, 11, 4 e 6\% de ocorrência, respectivamente. As espécies monocotiledôneas, Commelina benghalensis e gramíneas, representaram 10 e 27\% da infestação, respectivamente. Nos 3\% restantes encontravam-se outras espécies de plantas daninhas dicotiledôneas (Ipomoea spp., Alternanthera tenella, Tridax procumbens, Euphorbia heterophylla e Portulaca oleracea), que, além da baixa densidade, apresentavam desuniformidade de infestação.

As gramíneas incluíam Cenchrus echinatus, Digitaria horizontalis e plantas voluntárias de sorgo, milheto forrageiro e capim-pé-degalinha, oriundas das sementes produzidas pelas coberturas e depositadas no solo juntamente com os outros resíduos vegetais. Apesar da alta densidade de plantas de gramíneas, 67 plantas $\mathrm{m}^{-2}$ em média, não houve a avaliação por espécie, visto que a infestação era desuniforme para algumas delas e concentrada para as outras nos tratamentos em que suas sementes foram produzidas.

Os resultados foram submetidos ao teste F da análise de variância. Os efeitos do tipo e da quantidade de palha, quando significativos, foram comparados pelo teste de Tukey a 5\% de probabilidade. Por contrastes, fez-se a comparação entre a testemunha sem cobertura e os tratamentos com palha. Os dados de números de plântulas emergidas, nas duas épocas de avaliação, foram transformados em $(x+0,5)^{1 / 2}$.

\section{RESULTADOS E DISCUSSÃO}

Por meio da análise de variância, verificouse que houve efeito significativo da interação 
entre tipos e niveis de cobertura na emergência de Bidens pilosa, Commelina benghalensis, Amaranthus spp. e Chamaesyce spp., nas duas épocas de avaliação, e de Leucas martinicensis aos 75 dias após quantificação (DAQ) da palha. Para matéria seca, a interação entre os fatores foi significativa para B. pilosa, C. benghalensis e L. martinicencis. As coberturas influenciaram a emergência e a matéria seca de plantas de todas as espécies, com exceção de Bidens pilosa aos 14 DAQ. Os niveis de palha foram significativos para emergência de $B$. pilosa aos 14 e 75 DAQ e de L. martinicensis e Chamaesyce spp. aos 14 DAQ.

Como pode ser observado na Tabela 1, para B. pilosa, aos $14 \mathrm{DAQ}$, as coberturas não diferiram estatisticamente entre si nos seus maiores níveis. Apenas para a cobertura de sorgo houve aumento significativo na emergência de plântulas com a redução da quantidade de palha sobre o solo. Aos 75 DAQ, constatou-se menor número de plântulas no maior nivel de palha de sorgo, nos dois níveis de capim-pé-de-galinha e no menor nível de braquiária, o que foi refletido no acúmulo de matéria seca de plantas.

Por contrastes, verificou-se que o número de plântulas emergidas na testemunha sem palha foi estatisticamente superior ao dos demais tratamentos estudados, em ambos os niveis de palha. A matéria seca das plantas de
B. pilosa nos dois niveis de palha de milheto de forrageiro e no maior de braquiária não diferiu significativamente da testemunha.

Neste trabalho, como foi relatado, para determinados tipos de cobertura apenas $3 \mathrm{t} \mathrm{ha}^{-1}$ foram capazes de inibir, além da emergência, o crescimento e o desenvolvimento de B. pilosa, podendo-se afirmar que, em estudos dessa natureza, o tipo de cobertura é um fator de suma importância, visto que, em quantidades similares, há respostas distintas entre as coberturas para uma mesma espécie de planta daninha. Isso pode ser justificado pela sua constituição química, associada ou não às propriedades alelopáticas, e até mesmo pela geometria do resíduo vegetal, que condicionará uma cobertura mais eficiente do solo.

Uma possivel explicação para o efeito inibitório da palha sobre plantas daninhas seria a diminuição da quantidade e modificação da qualidade da luz que atinge as sementes depositadas na superfície do solo (Theisen et al., 2000). Sabe-se que as sementes de $B$. pilosa podem germinar tanto em condições de luz como de escuro (Reddy \& Singh, 1992; Amaral \& Takaki, 1993) e que a emergência de plântulas diminui linearmente com o aumento da profundidade de semeadura (Reddy \& Singh, 1992). No sistema de semeadura direta sem palha, em que as sementes de plantas daninhas permanecem na superfície do terreno, porém

Tabela 1 - Emergência e acúmulo de matéria seca de plantas de Bidens pilosa submetidas a quatro tipos de cobertura e dois níveis de palha, além da testemunha (sem palha). Uberlândia-MG, 2003/2004

\begin{tabular}{|c|c|c|c|c|c|c|}
\hline \multirow{4}{*}{ Tipo de cobertura } & \multicolumn{4}{|c|}{ Número de plântulas $\mathrm{m}^{-2}$} & \multirow{2}{*}{\multicolumn{2}{|c|}{$\begin{array}{c}\text { Matéria seca }\left(\mathrm{g} \mathrm{m}^{-2}\right) \\
75 \mathrm{DAQ}\end{array}$}} \\
\hline & \multicolumn{2}{|c|}{$14 \mathrm{DAQ}$} & \multicolumn{2}{|c|}{$75 \mathrm{DAQ}$} & & \\
\hline & \multicolumn{6}{|c|}{ Níveis de palha $\left(\mathrm{t} \mathrm{ha}^{-1}\right)$} \\
\hline & 3,0 & 5,5 & 3,0 & 5,5 & 3,0 & 5,5 \\
\hline Sorgo & $68,5 \mathrm{~b} \quad \mathrm{~B}$ & 0,5 a $\mathrm{A}$ & 107,0 b $\mathrm{B}$ & 2,0 a $\mathrm{A}$ & $94,28 \mathrm{ab} A$ & 47,80 a $\mathrm{A}$ \\
\hline Milheto forrageiro & 26,0 a $A$ & $11,0 \mathrm{a} \mathrm{A}$ & $108,0 \mathrm{~b} \mathrm{~A}$ & $81,0 \mathrm{~b} \quad \mathrm{~A}$ & $167,20 \mathrm{~b} \quad \mathrm{~A}$ & 190,16 b A \\
\hline Capim-pé-de-galinha & 17,0 a $\mathrm{A}$ & 11,0 a $\mathrm{A}$ & 42,0 a $A$ & 17,0 a $\mathrm{A}$ & $39,00 \mathrm{a}$ & $20,80 \mathrm{a} \mathrm{A}$ \\
\hline Braquiária & 20,0 a $\mathrm{A}$ & $15,0 \mathrm{a} \mathrm{A}$ & 51,0 a $\mathrm{A}$ & $120,0 \mathrm{~b} \mathrm{~B}$ & 38,68 a B & $251,84 \mathrm{~b} \mathrm{~A}$ \\
\hline DMS (na linha) & \multicolumn{2}{|c|}{1,74} & \multicolumn{2}{|c|}{2,56} & \multicolumn{2}{|c|}{97,34} \\
\hline DMS (na coluna) & \multicolumn{2}{|c|}{2,92} & \multicolumn{2}{|c|}{3,10} & \multicolumn{2}{|c|}{122,67} \\
\hline Testemunha sem palha & \multicolumn{2}{|c|}{139,5} & \multicolumn{2}{|c|}{286,0} & \multicolumn{2}{|c|}{180,44} \\
\hline
\end{tabular}

DAQ = dias após a quantificação da palha.

Com base no teste de Tukey a 5\% de probabilidade, médias seguidas por letras minúsculas, nas colunas, comparam tipos de cobertura dentro de cada nível de palha, e por letras maiúsculas, nas linhas, os dois níveis para cada cobertura. Médias de número de plântulas obtidas dos dados originais, que foram transformados em $(x+0,5)^{1 / 2}$ para realização da análise estatística. 
sem cobertura morta sobre as mesmas, o que é comum em algumas áreas do cerrado, $B$. pilosa será uma das espécies favorecidas.

Para C. benghalensis (Tabela 2), em ambas as épocas de avaliação, constatou-se menor emergência de plântulas nos dois níveis de palha de sorgo e no menor de milheto forrageiro. Para matéria seca, não se verificou diferença entre as coberturas nos seus maiores niveis de palha.

Por meio da comparação por contrastes, observou-se que a emergência de C. benghalensis na testemunha sem palha foi superior à dos demais tratamentos estudados, nos dois niveis de palha, aos 14 DAQ. Aos $75 \mathrm{DAQ}$, a testemunha não diferiu apenas do menor nível de braquiária. A matéria seca das plantas no menor nivel de braquiária foi significativamente superior à da testemunha, que não diferiu dos demais tratamentos. Todavia, no menor nivel de Braquiaria brizantha houve incremento no acúmulo de massa das plantas dessa espécie

Quanto ao efeito da luz na germinação de sementes de $C$. benghalensis, foi relatado que a exposição à luz aumentou a germinação de quatro tipos de sementes (aéreas grande e pequena e subterrâneas grande e pequena), e as sementes subterrâneas foram as mais sensiveis à ausência de luz (Walker \& Evenson, 1985). No entanto, em outro trabalho, os quatro tipos de sementes desta espécie de planta daninha germinaram tanto em condições de luz como de escuro (Gongalez \& Haddad, 1995). Esses resultados contraditórios podem ser justificados pelas populações diferentes das quais foram obtidas as sementes e pelo fotoperíodo em que a semente foi amadurecida (Gonzalez \& Haddad, 1995).

Observa-se, na Tabela 3, o efeito dos tipos de palha sobre a emergência e matéria seca de gramíneas. O número de plântulas emergidas de gramíneas nas duas épocas de avaliação, assim como a matéria seca destas, foi maior na palha de capim-pé-de-galinha, onde se observou alta infestação do próprio capim-pé-degalinha. As plantas desta espécie produziram muitas sementes, as quais foram depositadas no solo com o manejo da cultura. No início do período chuvoso houve fluxo de emergência e as plântulas foram eliminadas com a dessecação. No entanto, novos fluxos de emergência foram observados, infestando a área, após a quantificação da palha.

Por contrastes, observou-se que a emergência de gramíneas na cobertura de capimpé-de-galinha foi superior à da testemunha sem palha, que não diferiu das demais coberturas, nas duas épocas de avaliação. O mesmo foi observado para matéria seca de plantas. No entanto, para esta variável a testemunha sem palha diferiu das coberturas de braquiária e milheto forrageiro, que apresentaram as menores médias.

Tabela 2 - Emergência e acúmulo de matéria seca de plantas de Commelina benghalensis submetidas a quatro tipos de cobertura e dois níveis de palha, além da testemunha (sem palha). Uberlândia-MG, 2003/2004

\begin{tabular}{|c|c|c|c|c|c|c|}
\hline \multirow{4}{*}{ Tipo de cobertura } & \multicolumn{4}{|c|}{ Número de plântulas $\mathrm{m}^{-2}$} & \multirow{2}{*}{\multicolumn{2}{|c|}{$\begin{array}{c}\text { Matéria seca }\left(\mathrm{g} \mathrm{m}^{-2}\right) \\
75 \mathrm{DAQ}\end{array}$}} \\
\hline & \multicolumn{2}{|c|}{$14 \mathrm{DAQ}$} & \multicolumn{2}{|c|}{$75 \mathrm{DAQ}$} & & \\
\hline & \multicolumn{6}{|c|}{ Níveis de palha $\left(\mathrm{t} \mathrm{ha}^{-1}\right)$} \\
\hline & 3,0 & 5,5 & 3,0 & 5,5 & 3,0 & 5,5 \\
\hline Sorgo & 0,0 a $\mathrm{A}$ & $0,5 \mathrm{a} \quad \mathrm{A}$ & $1,0 \mathrm{ab} \mathrm{A}$ & $5,0 \mathrm{a} \quad \mathrm{A}$ & 0,07 a $\mathrm{A}$ & $11,12 \mathrm{a} A$ \\
\hline Milheto forrageiro & 0,0 a $\mathrm{A}$ & $2,0 \mathrm{ab} \mathrm{A}$ & $0,0 \mathrm{a} \quad \mathrm{A}$ & $23,0 \mathrm{~b} \quad \mathrm{~A}$ & $0,00 \mathrm{a} \mathrm{A}$ & $27,04 \mathrm{a} \mathrm{B}$ \\
\hline Capim-pé-de-galinha & $2,0 \mathrm{a} \mathrm{A}$ & $6,0 \mathrm{~b} \quad \mathrm{~B}$ & $12,0 \mathrm{~b} \quad \mathrm{~A}$ & $7,0 \mathrm{ab} A$ & 7,16 a $A$ & $0,72 \mathrm{a} A$ \\
\hline Braquiária & $12,0 \mathrm{~b} \quad \mathrm{~B}$ & $2,0 \mathrm{ab} A$ & 86,0 c B & $8,0 \mathrm{ab} A$ & $55,76 \mathrm{~b} \mathrm{~B}$ & 6,16 a $A$ \\
\hline DMS (na linha) & \multicolumn{2}{|c|}{0,58} & \multicolumn{2}{|c|}{1,41} & \multicolumn{2}{|c|}{24,88} \\
\hline DMS (na coluna) & \multicolumn{2}{|c|}{1,18} & \multicolumn{2}{|c|}{2,59} & \multicolumn{2}{|c|}{31,09} \\
\hline Testemunha sem palha & \multicolumn{2}{|c|}{38,0} & \multicolumn{2}{|c|}{66,0} & \multicolumn{2}{|c|}{19,64} \\
\hline
\end{tabular}

DAQ = dias após a quantificação da palha.

Com base no teste de Tukey a 5\% de probabilidade, médias seguidas por letras minúsculas, nas colunas, comparam tipos de cobertura dentro de cada nível de palha, e por letras maiúsculas, nas linhas, os dois níveis para cada cobertura. Médias de número de plântulas obtidas dos dados originais, que foram transformados em $(x+0,5)^{1 / 2}$ para realização da análise estatística. 
Tabela 3 - Emergência e acúmulo de matéria seca de plantas de gramíneas submetidas a quatro tipos de cobertura, além da testemunha (sem palha). Uberlândia-MG, 2003/2004

\begin{tabular}{|l|c|c|c|}
\hline \multirow{2}{*}{ Tipos de cobertura } & \multicolumn{2}{|c|}{ Número de plântulas $\mathrm{m}^{-2}$} & Matéria seca \\
\cline { 2 - 3 } & $14 \mathrm{DAQ}$ & $75 \mathrm{DAQ}$ & $\begin{array}{c}\left.\mathrm{g} \mathrm{m}^{-2}\right) \\
75 \mathrm{DAQ}\end{array}$ \\
\hline Sorgo & $2,0 \mathrm{a}$ & $19,0 \mathrm{a}$ & $89,36 \mathrm{c}$ \\
\hline Milheto forrageiro & $0,5 \mathrm{a}$ & $11,0 \mathrm{a}$ & $40,08 \mathrm{~b}$ \\
\hline Capim-pé-de-galinha & $116,0 \mathrm{~b}$ & $235,0 \mathrm{~b}$ & $295,80 \mathrm{~d}$ \\
\hline Braquiária & $0,5 \mathrm{a}$ & $4,5 \mathrm{a}$ & $0,80 \mathrm{a}$ \\
\hline DMS & 2,65 & 4,76 & 35,18 \\
\hline Testemunha sem palha & 11,0 & 43,0 & 75,60 \\
\hline
\end{tabular}

DAQ = dias após a quantificação da palha.

Médias seguidas pela mesma letra não diferem significativamente entre si pelo teste de Tukey a $5 \%$ de probabilidade. Médias de número de plântulas obtidas dos dados originais, que foram transformados em $(x+0,5)^{1 / 2}$ para realização da análise estatística.

As espécies do gênero Amaranthus observadas neste trabalho foram $A$. spinosus, A. retroflexus e A. hybridus. Para elas (Tabela 4), aos 14 e 75 DAQ, houve maior emergência de plântulas no menor nivel de sorgo, no maior de capim-pé-de-galinha e nos dois de capimbraquiária. O acúmulo de massa das plantas deste gênero foi maior sobre a palha de braquiária.

Através da análise por contrastes, verificou-se que a emergência de Amaranthus spp. na testemunha sem palha foi superior à dos demais tratamentos, nos dois niveis de palha, nas duas épocas de avaliação, com exceção do maior nível de capim-pé-de-galinha e do menor de sorgo, que não diferiram da testemunha, aos 14 DAQ. Para matéria seca de plantas, a testemunha sem palha não diferiu apenas da cobertura de braquiária.

As sementes dessas espécies de planta daninha são muito pequenas, portanto com reserva energética reduzida no endosperma, o que restringe a profundidade do solo em que as plântulas possam emergir na superfície (GhorbanI et al., 1999). Com a presença de palha sobre o solo, as sementes, mesmo aquelas depositadas na superfície, deparamse com uma barreira física formada pela cobertura morta, resultando no seu esgotamento energético antes de a plântula alcançar a superfície e iniciar o processo fotossintético.

Quanto à sensibilidade à luz, Gallagher \& Cardina (1998) mencionaram que a germinação das espécies $A$. retroflexus e $A$. hybridus é geralmente maior quando as sementes são expostas à luz vermelha, comparada à germinação no escuro. Entretanto, a luz pode ser uma exigência para a germinação apenas daquelas sementes mais dormentes no banco de sementes do solo.

Aos 14 DAQ, para L. martinicensis (Tabela 5), a interação entre tipos e níveis de cobertura não foi significativa, enquanto as coberturas afetaram o número de plântulas

Tabela 4 - Emergência e acúmulo de matéria seca de plantas de Amaranthus spp. submetidas a quatro tipos de cobertura e dois níveis de palha, além da testemunha (sem palha). Uberlândia-MG, 2003/2004

\begin{tabular}{|c|c|c|c|c|c|}
\hline \multirow{4}{*}{ Tipo de cobertura } & \multicolumn{4}{|c|}{ Número de plântulas $\mathrm{m}^{-2}$} & \multirow{4}{*}{$\begin{array}{c}\text { Matéria seca } \\
\left(\mathrm{g} \mathrm{m}^{-2}\right) \\
75 \mathrm{DAQ}\end{array}$} \\
\hline & \multicolumn{2}{|c|}{$14 \mathrm{DAQ}$} & \multicolumn{2}{|c|}{$75 \mathrm{DAQ}$} & \\
\hline & \multicolumn{4}{|c|}{ Níveis de palha $\left(\mathrm{t} \mathrm{ha}^{-1}\right)$} & \\
\hline & 3,0 & 5,5 & 3,0 & 5,5 & \\
\hline Sorgo & $6,0 \mathrm{~b} \quad \mathrm{~B}$ & 0,0 a $\mathrm{A}$ & $13,0 \mathrm{~b} \quad \mathrm{~B}$ & 0,0 a $\mathrm{A}$ & $5,92 \mathrm{a}$ \\
\hline Milheto forrageiro & $0,0 \mathrm{a} \quad \mathrm{A}$ & 0,0 a $\mathrm{A}$ & 1,0 a $\mathrm{A}$ & $1,0 \mathrm{a} \mathrm{A}$ & $0,36 \mathrm{a}$ \\
\hline Capim-pé-de-galinha & $0,0 \mathrm{a} \quad \mathrm{A}$ & $6,5 \mathrm{~b} \quad \mathrm{~B}$ & 0,0 a $\mathrm{A}$ & $12,0 \mathrm{~b} \quad \mathrm{~B}$ & $6,20 \mathrm{a}$ \\
\hline Braquiária & $3,0 \mathrm{ab} \mathrm{A}$ & $2,0 \mathrm{a} \mathrm{A}$ & $11,0 \mathrm{~b} A$ & $14,0 \mathrm{~b}$ A & $33,64 \mathrm{~b}$ \\
\hline DMS (na linha) & \multicolumn{2}{|c|}{0,93} & \multicolumn{2}{|c|}{1,39} & \\
\hline DMS (na coluna) & \multicolumn{2}{|c|}{1,14} & \multicolumn{2}{|c|}{1,61} & 19,40 \\
\hline Testemunha sem palha & \multicolumn{2}{|c|}{9,5} & \multicolumn{2}{|c|}{36,0} & 33,48 \\
\hline
\end{tabular}

DAQ = dias após a quantificação da palha.

Com base no teste de Tukey a 5\% de probabilidade, médias seguidas por letras minúsculas, nas colunas, comparam tipos de cobertura dentro de cada nível de palha, e por letras maiúsculas, nas linhas, os dois níveis para cada cobertura. Médias de número de plântulas obtidas dos dados originais, que foram transformados em $(x+0,5)^{1 / 2}$ para realização da análise estatística. 
Tabela 5 - Emergência e acúmulo de matéria seca de plantas de Leucas martinicensis submetidas a quatro tipos de cobertura e dois níveis de palha, além da testemunha (sem palha). Uberlândia-MG, 2003/2004

\begin{tabular}{|c|c|c|c|c|c|}
\hline \multirow{4}{*}{ Tipo de cobertura } & \multicolumn{3}{|c|}{ Número de plântulas $\mathrm{m}^{-2}$} & \multirow{2}{*}{\multicolumn{2}{|c|}{$\begin{array}{c}\text { Matéria seca } \\
\left(\mathrm{g} \mathrm{m}^{-2}\right) 75 \mathrm{DAQ}\end{array}$}} \\
\hline & \multirow{3}{*}{$14 \mathrm{DAQ}$} & \multicolumn{2}{|c|}{75 DAQ } & & \\
\hline & & \multicolumn{4}{|c|}{ Níveis de palha $\left(\mathrm{t} \mathrm{ha}^{-1}\right)$} \\
\hline & & 3,0 & 5,5 & 3,0 & 5,5 \\
\hline Sorgo & $3,0 \mathrm{~b}$ & $1,0 \mathrm{ab} \mathrm{A}$ & $20,0 \mathrm{~b} \quad \mathrm{~B}$ & 0,00 a $\mathrm{A}$ & $31,09 \mathrm{~b} \quad \mathrm{~B}$ \\
\hline Milheto forrageiro & $0,5 \mathrm{a}$ & $1,0 \mathrm{ab} \mathrm{A}$ & $1,0 \mathrm{a} \mathrm{A}$ & $0,15 \mathrm{aA}$ & $0,15 \mathrm{a} \mathrm{A}$ \\
\hline Capim-pé-de-galinha & $0,5 \mathrm{a}$ & $0,0 \mathrm{a} \quad \mathrm{A}$ & $2,0 \mathrm{aA}$ & 2,79 a $A$ & $1,81 \mathrm{a} \mathrm{A}$ \\
\hline Braquiária & $1,0 \mathrm{ab}$ & $20,0 \mathrm{~b} \quad \mathrm{~A}$ & 3,0 a $\mathrm{A}$ & 10,38 a $A$ & 1,99 a A \\
\hline DMS (na linha) & & \multicolumn{2}{|c|}{1,93} & \multicolumn{2}{|c|}{15,07} \\
\hline DMS (na coluna) & 0,70 & \multicolumn{2}{|c|}{2,59} & \multicolumn{2}{|c|}{19,79} \\
\hline Testemunha sem palha & 13,0 & \multicolumn{2}{|c|}{75,0} & \multicolumn{2}{|c|}{67,80} \\
\hline
\end{tabular}

DAQ = dias após a quantificação da palha.

Com base no teste de Tukey a 5\% de probabilidade, médias seguidas por letras minúsculas, nas colunas, comparam tipos de cobertura dentro de cada nível de palha, e por letras maiúsculas, nas linhas, os dois níveis para cada cobertura. Médias de número de plântulas obtidas dos dados originais, que foram transformados em $(x+0,5)^{1 / 2}$ para realização da análise estatística.

emergidas, com maior média sobre palha de sorgo. Aos 75 DAQ, houve incremento na emergência de plântulas no menor nível de braquiária e no maior de sorgo. Para matéria seca de plantas, as coberturas não diferiram entre si nos seus menores níveis, e, com o aumento da quantidade de palha de sorgo sobre o solo, o acúmulo de massa das plantas de $L$. martinicensis também foi aumentado.

Verificou-se, por contrastes, que a emergência e a matéria seca das plantas desta espécie na testemunha sem palha foram superiores às dos demais tratamentos, em ambos os niveis de palha.

Alguns resultados mostraram maior emergência de plantas daninhas no maior nível de palha, onde se esperava o contrário, ou ao menos uma similaridade de resposta entre os níveis. No entanto, embora a palha possa influenciar negativamente a germinação de sementes, esta também pode favorecer algumas espécies de plantas daninhas, através da redução na amplitude de variação térmica diária do solo, da conservação da umidade do solo ou, ainda, da melhoria química, física e biológica do solo, além da possível eliminação de substâncias alelopáticas, com a decomposição da cobertura morta, que poderia contribuir para a quebra da dormência de sementes. Assim, nos maiores niveis de palha, a planta daninha seria ainda mais beneficiada, extraindo da palha vantagens adaptativas.

Quanto à emergência de Chamaesyce spp. (Tabela 6), constatou-se que aos $14 \mathrm{DAQ}$ não houve diferença significativa entre os tipos de cobertura nos seus maiores níveis, enquanto com a redução da quantidade de palha de sorgo o número de plântulas emergidas aumentou significativamente. Posteriormente, aos 75 DAQ, constatou-se maior emergência nos dois níveis de palha de milheto forrageiro, o que influenciou a matéria seca das plantas.

Por contrastes, observou-se que, aos 14 DAQ, apenas o menor nível de sorgo diferiu da testemunha sem palha. Todavia, aos 75 DAQ, a testemunha não diferiu dos dois níveis de braquiária e do maior de sorgo. Para matéria seca, as plantas crescidas sobre cobertura de milheto forrageiro apresentaram maior massa, comparadas às da testemunha sem palha, que não diferiu dos demais tratamentos.

Observações de campo mostram aumento na infestação de Chamaesyce hirta em áreas de semeadura direta de culturas anuais na região do Triângulo Mineiro e Alto Paranaíba (Paes \& Rezende, 2001). Esta, juntamente com C. hyssopifolia, foram as espécies do gênero Chamaesyce observadas no presente experimento, não havendo predomínio de nenhuma delas. 
Tabela 6 - Emergência e acúmulo de matéria seca de plantas de Chamaesyce spp. submetidas a quatro tipos de cobertura e dois níveis de palha, além da testemunha (sem palha). Uberlândia-MG, 2003/2004

\begin{tabular}{|c|c|c|c|c|c|}
\hline \multirow{4}{*}{ Tipo de cobertura } & \multicolumn{4}{|c|}{ Número de plântulas $\mathrm{m}^{-2}$} & \multirow{4}{*}{$\begin{array}{c}\text { Matéria seca } \\
\left(\mathrm{g} \mathrm{m}^{-2}\right) \\
75 \mathrm{DAQ}\end{array}$} \\
\hline & \multicolumn{2}{|c|}{14 DAQ } & \multicolumn{2}{|c|}{75 DAQ } & \\
\hline & \multicolumn{4}{|c|}{ Níveis de palha $\left(\mathrm{t} \mathrm{ha}^{-1}\right)$} & \\
\hline & 3,0 & 5,5 & 3,0 & 5,5 & \\
\hline Sorgo & $4,5 \mathrm{~b} \quad \mathrm{~B}$ & 1,0 a $\mathrm{A}$ & $38,0 \mathrm{ab} B$ & $8,0 \mathrm{a} \quad \mathrm{A}$ & $7,56 \mathrm{ab}$ \\
\hline Milheto forrageiro & $2,0 \mathrm{ab} A$ & 1,0 a $\mathrm{A}$ & $58,0 \mathrm{~b} \quad \mathrm{~A}$ & $58,0 \mathrm{~b} \quad \mathrm{~A}$ & $14,60 \mathrm{~b}$ \\
\hline Capim-pé-de-galinha & $1,5 \mathrm{ab} \mathrm{A}$ & $1,0 \mathrm{a} \mathrm{A}$ & $32,0 \mathrm{ab} \mathrm{A}$ & $24,0 \mathrm{ab} \mathrm{A}$ & $4,12 \mathrm{ab}$ \\
\hline Braquiária & $0,5 \mathrm{a} \quad \mathrm{A}$ & 0,0 a $\mathrm{A}$ & $8,0 \mathrm{a} \quad \mathrm{A}$ & $5,0 \mathrm{a} \quad \mathrm{A}$ & $0,68 \mathrm{a}$ \\
\hline DMS (na linha) & \multicolumn{2}{|c|}{0,72} & \multicolumn{2}{|c|}{2,41} & \\
\hline DMS (na coluna) & \multicolumn{2}{|c|}{0,85} & \multicolumn{2}{|c|}{3,98} & 12,56 \\
\hline Testemunha sem palha & \multicolumn{2}{|c|}{0,0} & \multicolumn{2}{|c|}{0,0} & 0,00 \\
\hline
\end{tabular}

DAQ = dias após a quantificação da palha.

Com base no teste de Tukey a 5\% de probabilidade, médias seguidas por letras minúsculas, nas colunas, comparam tipos de cobertura dentro de cada nível de palha, e por letras maiúsculas, nas linhas, os dois níveis para cada cobertura. Médias de número de plântulas obtidas dos dados originais, que foram transformados em $(x+0,5)^{1 / 2}$ para realização da análise estatística.

Com o processo de decomposição da palha ocorre a liberação gradativa de uma série de compostos orgânicos denominados aleloquímicos, de origem vegetal ou microbiana, que podem interferir diretamente na emergência de plantas daninhas, assim como na perda da viabilidade de seus diásporos (Correia \& Durigan, 2004). Almeida (1991) relatou que os resíduos vegetais de decomposição rápida têm, geralmente, ação alelopática intensa, mas de curta duração, e os de decomposição lenta têm ação por mais tempo. A atividade alelopática depende diretamente do tipo e quantidade do material vegetal depositado na superfície, do tipo de solo, da população microbiana, das condições climáticas e da composição específica da comunidade de plantas daninhas.

Ressalta-se também que, com a deposição de material vegetal no solo, para aqueles com alta relação $\mathrm{C} / \mathrm{N}$, o nitrogênio mineral do solo é imobilizado pelos microrganismos que dele necessitam para a síntese de seus compostos celulares, chegando a desaparecer do solo durante o período de crescimento máximo da comunidade microbiana. Nesse período, dependendo das exigências nutricionais da espécie de planta daninha, esta pode ter o crescimento e o desenvolvimento inibidos, devido à escassez temporária de nitrogênio mineral do solo. Cardoso (1992) afirmou que somente na fase de declínio da comunidade microbiana o nitrogênio mineral volta a aparecer, sendo mineralizado pelos indivíduos vivos a partir das células microbianas mortas.

Com base nos resultados obtidos, pode-se concluir que a composição específica e as densidades populacionais das comunidades infestantes foram influenciadas pelos sistemas de produção de cobertura morta. A emergência das plantas daninhas foi menor nas coberturas de sorgo e Braquiária brizantha e nos maiores níveis de palha. A emergência de Bidens pilosa, Amaranthus spp., Commelina benghalensis, Leucas martinicensis e gramíneas foi inibida pelas coberturas, o que não foi observado para Chamaesyce spp.

\section{LITERATURA CITADA}

ALMEIDA, F. S. Controle de plantas daninhas em plantio direto. Londrina: IAPAR, 1991. 34 p. (IAPAR. Circular, 67)

AMARAL, A.; TAKAKI, M. Germinação de sementes de espécies invasoras de culturas. III. Bidens pilosa L. Arq. Biol. Tecnol., v. 36, n. 2, p. 401-408, 1993.

BUZATTI, W. J. S. Controle de plantas daninhas no sistema plantio direto na palha. In: PAULETTI, V.; SEGANFREDO, R. Plantio direto: atualização tecnológica. São Paulo: Fundação Cargill/Fundação ABC, 1999. p. 97-111. 
CARDOSO, E. J. B. N. Efeito da matéria orgânica na biologia do solo. In: GUERRINI, I. A.; THEODORO, L. (Eds.). ENCONTRO SOBRE MATÉRIA ORGÂNICA DO SOLO: PROBLEMAS E SOLUÇÕES, 1992, Botucatu. Anais... Botucatu: FCA/UNESP, 1992. p.37-62.

CORREIA, N. M.; DURIGAN, J. C. Emergência de plantas daninhas em solo coberto com palha de cana-de-açúcar.

Planta Daninha, v. 22, n. 1, p. 11-17, 2004.

DURIGAN, J. C.; ALMEIDA, F. L. S. Noções de alelopatia. Jaboticabal: Editora da FUNEP, 1993. 23 p.

GALLAGHER, R. S.; CARDINA, J. Phytochrome-mediated Amaranthus germination I: effect of seed burial and germination temperature. Weed Sci., v. 46, n. 1, p. 48-52, 1998.

GHORBANI, R.; SEEL, W.; LEIFERT, C. Effects of environmental factors on germination and emergence of Amaranthus retroflexus. Weed Sci., v. 47, n. 5, p. 505-510, 1999.

GONZALEZ, C. B.; HADDAD, C. R. B. Efeito da luz e temperatura na floração e germinação de sementes de Commelina benghalensis L. Arq. Biol. Tecnol., v. 38, n. 2, p. 651-659, 1995.

MATEUS, G. P.; CRUSCIOL, C. A. C.; NEGRISOLI, E. Palhada do sorgo de guiné gigante no estabelecimento de plantas daninhas em área de plantio direto. Pesq. Agropec. Bras., v. 39, n. 6, p. 539-542, 2004.

NAGABHUSHANA, G. C.; WORSHAM, A. D.; YENISH, J. P. Allelopatic cover crops to reduce herbicide use in sustainable agricultural systems. Allelop. J., v. 8, n. 2, p. 133-146, 2001.
OLIVEIRA, M. F. et al. Efeito da palha e da mistura atrazine e metolachlor no controle de plantas daninhas na cultura do milho, em sistema de plantio direto. Pesq. Agropec. Bras., v. 36, n. 1, p. 37-41, 2001.

PAES, J. M. V.; REZENDE, A. M. Manejo de plantas daninhas no sistema plantio direto na palha. Inf. Agropec., v. 22, n. 208, p. 37-42, 2001.

PITELLI, R.; DURIGAN, J. C. Ecologia das plantas daninhas no sistema de plantio direto. In: ROSSELLO, R. D. Siembra directa en el Cono Sur. Montevideo: PROCISUR, 2001. p. 203-210.

REDDY, N. K.; SINGH, M. Germination and emergence of hairy beggarticks (Bidens pilosa). Weed Sci., v. 40, n. 2, p. 195-199, 1992.

THEISEN, G.; VIDAL, R. A. Efeito da cobertura do solo com resíduos de aveia preta nas etapas do ciclo de vida do capim-marmelada. Planta Daninha, v. 17, n. 2, p. 189-196, 1999.

THEISEN, G.; VIDAL, R. A.; FLECK, N. G. Redução da infestação de Brachiaria plantaginea em soja pela cobertura do solo com palha de aveia preta. Pesq. Agropec. Bras., v. 35 , n. 4 , p. $753-756,2000$.

TREZZI, M. M.; VIDAL, R. A. Potencial de utilização de cobertura vegetal de sorgo e milheto na supressão de plantas daninhas em condição de campo: II - efeitos da cobertura morta. Planta Daninha, v. 22, n. 1, p. 1-10, 2004.

WALKER, S. R.; EVENSON, J. P. Biology of Commelina benghalensis L. in south-eastern Queensland. 2. Seed dormancy, germination and emergence. Weed Res., v. 25, p. 245-250, 1985. 